\title{
Transform your human resources processes to improve your patient's care, quality, and results
}

\author{
A. Boukhobza, T. Etchebarne \\ Former directors of companies and managers
}

\author{
SUMMARY
}

The purpose of this article is to identify what are the human resources processes to be implemented in orthodontic practices to both improve the management of patients, but also the profitability of the structure in terms of both organization and financial.

The work on the cohesion of the teams will create a collective commitment which depends on the one hand on the quality of the recruitment of the employees, and then on the motivation levers set up within the teams and maintained over time. In the teams the intergenerational collaboration must be managed and optimized.

On the other hand, the orthodontist leader must have a clear strategy and clear objectives to be able to communicate effectively. He must also know the communication tools according to the circumstances to convey the messages he needs.

\section{KEYWORDS}

Management, strategy, HR process, time management, organization, motivation, cohesion, change, recruitment, integration, engagement, loyalty, "intergenerational," profitability, communication, trust, sense, decision, control, anticipation, emotional intelligence.

\section{FORMALIZE THE LINK BETWEEN STRATEGY} AND "HUMAN RESOURCE PROCESSES"

\section{Can we talk about strategy in dental and orthodontic practices?}

Dentists and orthodontists are health professionals who serve the patient.

As for doctors, the relationship with the patient and the notion of trust are at the heart of these professions.

This observation seems to distance them a priori from the world of business.
And yet, could we not get out of the WHERE and consider a dental or orthodontics practice to be both a service to the patient AND also a very specialized company: a health company.

If we adopt this perspective, it is interesting to define the key players in the practice who can assist the practitioner both in patient care and practice management.

Address for correspondence:

Albert Boukhobza - 11, allée des Hêtres - 78350

Jouy-en-Josas - France

E-mail: a.boukhobza@connecsens.com

Article received: 14-01-2018. Accepted for publication: 21-03-2018.

This is an Open Access article distributed under the terms of the Creative Commons Attribution License (http://creativecommons.org/licenses/by/4.0), which permits unrestricted use, distribution, and reproduction in any medium, provided the original work is properly cited. 
Within the practices and according to their importance, one encounters various types of professions: dental assistants, executive assistants, medical secretaries, administrative secretaries, and accountants.

What proportion of the practitioner's time is spent on clinical and administrative tasks?

According to studies conducted by the Edmond Binhas Group, statistics show that a practitioner working alone spends approximately $50 \%$ of their time out of the dentist's chair. This percentage is reduced to $30 \%$ when they are assisted by an assistant to whom they can delegate non-clinical tasks.

First, what are the specific features of a practice?

The oral surgeon or orthodontist carries out his or her clinical tasks by relying on both an internal care team in the office-as a dental assistant, administrative assistant, and medical secretary-as well as on external partners, such as a prosthetist.

The practitioner therefore has both a moral responsibility toward their patient and medical team and a management responsibility vis-à-vis their health company: their practice.

To assume this dual responsibility, they can hardly work alone, and they therefore need, on the one hand, motivated employees at the service of their patients, and on the other hand, to know how to mobilize the energy available in the practice to service their vision and development strategy.

When they put on their management hat, they assume both the role of a leader's, who is responsible for the elaboration of their vision of the future and development strategy, as well as that of a manager.

The image of an effective leader is that of one who catalyzes the commitment of their staff and the pursuit of a clear and indisputable vision by stimulating higher levels of results.

An effective manager is one who assumes the fluid responsibility to lead their team by asserting their unequivocal power at the right time, to lead and motivate, to manage face-to-face situations of tension or conflict, to manage their time and that of their staff, to be in control of changes, to manage financial and cash flow aspects, and to detect and solve potential problems.

We will first discuss the practitioner's leadership role, which is responsible for developing the practice's strategic objectives and then the relationship between these objectives and the main

"human resources" processes to integrate into the daily action of the practice to promote success.

\section{What can be the strategic objec- tives of a practice?}

They include 1-, 2-, and 3-year clinical goals such as maintaining or increasing the quality of clinical protocols, providing treatment for patients based on the latest scientific evidence, and improving quality of care and patient management.

They also include entrepreneurial strategic objectives relating to the expected evolution of turnover, expected profitability within 2 or 3 years, level of investment required to support the strategy, available cash flow, and cash that will need to be mobilized externally. 


\section{What are the main human resource processes to consider?}

Five areas seem particularly important: team cohesion, recruitment and integration of new employees, motivation, commitment and retention of team members, intergenerational collaboration, and management and communication within the practice.

PROCESS NO. 1:

\section{TEAM COHESION}

Team cohesion of those working within the same practice results in an improvement of collaboration quality between members of different departments: practitioners, dental assistants, and administrative assistants.

First, it should be noted that improving the quality of collaboration cannot be decreed and the achievement of this objective is more a matter of regular development over weeks and months.

The evolution from a rather vertical practice culture "Patient, Practitioner, Assistant, Administrator" toward a more horizontal culture emphasizing the collective would be promoted by the implementation of the following values and actions: collective mindset, regular exchange and sharing of information, mutual support, and daily establishment of teamwork.

There are natural obstacles to this implementation: personality differences that complicate understanding and communication; partial knowledge of the colleague's roles, objectives, and tasks; and the persistence of old beliefs or habits, such as the idea that "sharing information is giving up power and putting my role at risk" or "working alone is better than working in a team."
These obstacles, if not anticipated and identified, can lead to a waste of time, energy, quality, and performance.

What are the main factors that will promote the implementation of strong cohesion and therefore a good collaboration, sustainable quality of patient service, and performance of the practice?

- First, create a strong sense of belonging within the practice (determine a vision).

- Encourage information exchange and feedback.

- Alternate the communication of top-down instructions and regularly consult with the teams.

- Give recognition by valuing individual or collective achievements during face-to-face interviews and also during team meetings.

- Clarify and formalize the practice's collective mission and the expected roles and contributions of each member.

- Check the staff's appropriation of the vision by encouraging reformulation.

- Explain the practice's operating rules and make them evolve over 
time using continuous improvement processes.

- Clarify the scope of responsibility of each member and even the delegations of authority granted.

- Explain the decision-making process by encouraging initiative among the teams.

- Promote a gradual increase in team autonomy, neither too quick- ly so as not to generate stress nor too slowly so as not to keep staff in their comfort zone, which would be detrimental to the practice.

- Organize short and regular team meetings, formalized by a recording of the meeting's minutes to document the decisions made and the person responsible for their implementation.

PROCESS NO. 2:

\section{RECRUITMENT AND INTEGRATION}

How can it be explained that the stock market valuation of a company such as Linkedln created in 2000 exceeds that of Peugeot or that Airbnb, founded in 2008, already earns twice as much as the hotel group Accor and its 482,000 rooms around the world?

This is because these companies have been able to imagine and design the best products and services in their respective markets. However, competition is particularly fierce in the digital economy world.

These companies that stand out from the crowd have one thing in common: they pay close attention to the motivation and potential of each person who joins them to contribute to their success; they rely on their teams and on permanent innovations in human resources.

In the field of dentistry and orthodontics, technology is obviously important, and new products or services aim to improve the comfort of the practitioner or the patient.
However, technology in the medical world and in the digital economy is no substitute for human relationships.

We must keep in mind that mistakes in recruitment can quickly result in patient losses, dysfunctions in the office, and ultimately in financial losses.

A good recruitment program is characterized by the following:

- The staff member easily manages to achieve their goals.

- They seamlessly integrate into the team.

- They quickly understand the practice's culture.

- They adapt quickly to its evolution.

- They become invaluable to practitioners because they find concrete solutions to the practitioner's objectives, demands, and expectations.

Achieving good recruitment and integration requires following a few rules: 
- Write a detailed job description.

- Provide time for the recruit to integrate into the position.

- Explicitly detail all expectations.

- Closely monitor the progress and difficulties of the new employee in the first months.

- Give them regular feedback on the expected evolution of their technical skills, their behavior, and whether or not they have aligned with the culture of the practice.

- Beyond these points, the manager of the practice must clearly iden- tify the constraints related to the private life of the staff member as well as any possible leeway that should be given to them.

- Finally, plan a formal evaluation of the new employee once a year.

The ease with which a practitioner attracts the best talent depends on many other factors that can be identified. Sometimes, it is necessary to rely on an external audit.

PROCESS NO. 3:

\section{DEVELOP, RETAIN, AND MOTIVATE STAFF MEMBERS}

What skills are being sought today?

Being competent in one's work requires a mix of technical skills (hard skills), behavioral skills (soft skills), and business skills (mastery of the challenges and culture of the business sector).

Compared with existing professions in orthodontic practices, this amounts to analyzing the evolution of practices in the years to come.

In business, the skills that will enable us to remain competitive in today's world, characterized by an increase in uncertainty and complexity, revolve around the following areas of expertise: distance collaboration, entrepreneurship, initiative, communication via digital technology, agility and adaptation, creativity and innovation, ability to organize effectively, and learning how to learn.

Apart from remote collaboration, all the others can be applied to the world of medical practices in the broad sense, with entrepreneurship becom- ing a team spirit, mutual aid, and a perception of the practice's interest.

\section{How to motivate employees}

To put it simply, the leader must realize the following:

- They cannot always motivate and engage with their employees.

- They can, however, contribute to it by paying particular attention to the atmosphere in the practice.

- They can also enhance their listening skills as well as the frequency of positive feedback given to staff and assistants.

- Of course, they can play on the leverage of remuneration, but salary is not an intrinsic motivating factor. It can even be a demotivating factor if it is below the average of other practices. 
On the other hand, they can help to increase the motivation and commitment of their employees by implementing some winning habits:

- Ensuring a friendly atmosphere

- Maintaining good working conditions

- Making training available

- Listening
- Giving recognition

- Organizing events within the practice

- Giving meaning to their professional experience and daily actions; this occurs when employees perceive that their interests are taken into account beyond the interest of the practice.

PROCESS NO. 4:

\section{EFFECTIVELY MANAGING COLLABORATION IN INTERGENERATIONAL TEAMS}

Until 2010, the generation of baby boomers, representing people born before 1960, was the workforce majority. This trend has now been reversed and it is estimated that by 2020, Generation Y (born between 1980 and 1995) will represent $>55 \%$ of the workforce.

As intergenerational management is the ability of a company to effectively bring together people of different generations, we easily understand the importance of this process.

The objectives and challenges are to identify the evolution of techniques and practices, to update the existing protocols, to transfer knowledge and expertise within the practice, and to integrate the younger generation (Generation Y) while maintaining team cohesion.

This process of intergenerational collaboration at work can be transformed into a differentiating advantage.
It is essential to abandon prejudices or at least take a step back, as an effective intergenerational management requires a non-judgmental approach. No generation is better than another; each one has its own characteristics that the leader must make the best possible use of.

By mixing employees from different generations in each team, we get the most successful teams because they bring together different people who benefit from differing skills and opinions. Mentoring and valid rules of conduct for all are proving to be very effective tools.

The application of these rules will create necessary conditions for successful intergenerational management. These necessary conditions can then be supplemented by identifying the specific expectations of each generational group and by making decisions on how to at least partially integrate these expectations. 
PROCESS NO. 5 :

\section{OPTIMIZING MANAGEMENT AND COMMUNICATION}

Good management means fully assuming the role of the manager and

\section{Fulfilling the role of the manager}

The key functions of a manager are as follows:

- Give meaning and confidence

- Meaning by formalizing the practice's mission.

- Confidence by reassuring employees about their skills, giving feedback, and demonstrating coherent speech and actions.

- Show and ask staff to set an example of professional behavior.

- Organize

- Define positions by setting objectives and responsibilities.

- Define who can decide what.

- Set up necessary delegations, and identify the methods to be provided to the staff.

- Decide

- Know how to analyze and quantify the possible options. Collect and synthesize the points of view of everyone present. Identify the common ground between everyone present and individual interests.

- Know how to make decisions at the right time.

- Ensure adherence by setting application criteria that are understood and recognized. demonstrating emotional intelligence and communication skills.

- Give staff the means and autonomy to assume their responsibilities.

- Assume the consequences, monitor the application, and correct if necessary.

- Motivate

- Develop collaboration among staff through paired or practice-wide projects, for example.

- Take into account ideas and suggestions. Circulate information transparently.

- Verify

- Set up indicators to measure the quality of patient care, the quality of protocol application, efficiency, time management, and costs.

- Appreciate, evaluate, and reward individual and collective contributions.

- Anticipate

- Allow everyone to acquire the necessary skills to adapt to the clinical and technological developments of the profession (training).

These necessary conditions can then be completed by gradually identifying the expectations of each generational group to set up a more personalized management. 


\section{Demonstrating emotional intelligence}

Emotional intelligence is a concept that refers to the ability to recognize, understand, and control one's own emotions and deal with other people's emotions.

The manager must understand their own strengths and positive emotions, which is a source of energy for them and their teams, to understand the factors related to their personality and the triggers of negative emotions and sources of stress; to know how to manage their emotional balance and stress in situations of relational tension; to be able to identify the emotions of others, stressors for the team, and the predictable reactions of employees to this stress; to know how to react in a fair and adapted way; and to know how to express and share their feelings.

Psychometric, individual, and collective tests, e.g., Process com or DynaStrat, can allow one to progress quickly on this subject.

\section{Knowing how to communicate}

Good communication is paramount. To be effective, communication must enable employees to understand the message, adhere to it, take ownership of it, and take effective action.

Different communication situations can be encountered:

\section{Communication of decisions}

The information must be clear and concise so that the collaborator understands the purpose, what to do, and when. It is important that the staff checks their understanding and makes sure that they have the skills and the means to implement it correctly.

\section{Communication in usual situations}

It has the same characteristics as the previous point. The manager must bring out a sense of security so that the employee works responsibly.

Reframing communication, situations, or behaviors that are unsuitable

To be effective, the four steps must be respected: communication of the facts observed and reminder of the rule, if there is a failure, information of the consequences and the manager's feelings in relation to the situation, communication of the needs of the practice, so in general, requests made to the staff must be stated explicitly.

\section{CONCLUSION}

The application of these processes should significantly improve patient management, the quality of the clinical and administrative protocols, and the atmosphere and climate of collaboration within the team, and consequently, should also generate positive financial impacts for the practice.

Tips for ongoing success:

Perform a test like Process Communication to avoid unpleasant surprises during the integration. 
For orthodontic practitioners practicing alone, be aware of the importance of taking temporary external counseling to be able to pass a course. There is, of course, a cost involved in consulting, but the right approach is to compare that cost with the benefits that this improvement process will generate.

\section{Conflict of interest}

The authors state that there is no conflict of interest

\section{WORKS TO CONSULT}

1. Baranski L. The enlightened manager. Eyrolles.

2. Johnson K, Autissier D, Giraud L. The 100 patterns of management. Eyrolles, 2015; p. 228.

3. Le Saget M. The Intuitive Manager. Paris, Dunod, 2013, p. 320.

4. Pink DH, Getz I. The truth about what motivates us. Flammarion, 2016; p. 254.

5. Ramanantsoa B. The art of management. Pearson, 2008; p. 240.

6. Remy C. The patient-practitioner relationship facilitated by a cohesive team. Thesis for the diploma for a doctorate in dental surgery. University of Lorraine, Faculty of Dental Surgery.

7. Stern P, Schoettl JM. The management toolbox: 64 tools and methods. 2nd edition, Paris, Dunod, 2017; p. 192.

8. JPTesta, Lafargue J, Tilhet-Cohartet V. The Leadership Toolkit: 59 Tools and Methods. 2nd edition, Paris, Dunod, 2017; p. 192. 